\title{
Correction to: Residual Renal Function and Obstructive Sleep Apnea in Peritoneal Dialysis: A Pilot Study
}

\author{
Aviya Lanis $^{1}$ - Eric Kerns ${ }^{1,3,4}$. Susie L. Hu ${ }^{1,3,4}$. Margaret H. Bublitz ${ }^{1,3}$ - Patricia Risica ${ }^{2}$. Susan Martin ${ }^{3}$. Jeffrey Parker ${ }^{5}$. \\ Richard Millman ${ }^{1,4}$. Lance D. Dworkin ${ }^{1,4}$. Ghada Bourjeily ${ }^{1,3,4,6}$
}

Published online: 25 June 2018

○) Springer Science+Business Media, LLC, part of Springer Nature 2018

\section{Correction to: Lung \\ https://doi.org/10.1007/s00408-018-0127-5}

The original version of this article unfortunately contained a mistake in the article title. The correct article title is "Residual Renal Function and Obstructive Sleep Apnea in Peritoneal Dialysis: A Pilot Study".

The original article can be found online at https://doi.org/10.1007/ s00408-018-0127-5.

Ghada Bourjeily

ghada_bourjeily@brown.edu

1 Alpert Medical School of Brown University, 222 Richmond Street, Providence, RI, USA

2 Center for Health Equity Research, Brown School of Public Health, 121 South Main Street, Providence, RI, USA

3 The Miriam Hospital, 164 Summit Avenue, Providence, RI, USA

4 Rhode Island Hospital, 594 Eddy Street, Providence, RI, USA

5 Rhode Island Hospital Sleep Disorder Center, 450 Veterans Memorial Parkway, East Providence, RI, USA

6 Providence, USA 